\title{
ANALISIS KEMULURAN RANTAI ORIGINAL HONDA CB150R
}

TAHUN 2015

\author{
Maman Nurjaya ${ }^{1}$, TB. Utami Adi Subekhi ${ }^{2}$, Yadi Heryadi ${ }^{3}$ \\ ${ }^{1}$ stt - wastukancana \\ ${ }^{1}$ mamannurjaya234@gmail.com \\ 2tb.subekhi@stt-wastukancana.ac.id \\ 3y4dib3nz@gmail.com
}

\begin{abstract}
Abstrak - Sepeda motor merupakan satu dari berbagai sarana transportasi darat yang cocok digunakan untuk menjangkau berbagai daerah dan tempat terpencil dengan pertimbangan ongkos yang murah. Sepeda motor dapat dinaiki sendiri ataupun dengan penumpang dibelakangnya. Kekuatan suatu rantai kendaraan merupakan masalah yang sangat penting pada performa kendaraan. Rantai yang mengalami kemuluran akan menyebabkan menurunnya performa. Dengan melakukan pengujian tarik pada rantai kita bisa mendapatkan data yang bisa kita butuhkan untuk mencari tegangan, regangan dan juga kemuluran pada rantai. Tegangan yang terjadi pada pengujian pertama sebesar $2898.21 \mathrm{~N} / \mathrm{mm}^{2}$, regangan sebesar 0,43 , modulus elastis sebesar 6481.07 $\mathrm{N} / \mathrm{mm}^{2}$, serta kemuluran sebesar $12.5556 \mathrm{~mm}$. Dan tegangan pada pengujian kedua sebesar $2924.40 \mathrm{~N} / \mathrm{mm}^{2}$, regangan sebesar 0,47, modulus elastis sebesar $6222.12 \mathrm{~N} / \mathrm{mm}^{2}$, serta kemuluran 12,6108 mm.
\end{abstract}

Kata Kunci : rantai, tegangan regangan modulus elastis, dan kemuluran.

Abstract - Motorcycles are one of a variety of suitable means of land transportation used to reach remote regions and places deng $n$ consideration of a cheap fare. Motorcycle can be ridden alone or with passengers behind it. The strength of a vehicle chain is a very important issue in vehicle performance. A chain that is stretched will cause a decrease in performance. By doing tensile testing on the chain we can get the data we can need to find stress, strain and elongation in the chain. The stress that occurs in the first test is $2898.21 \mathrm{~N} /$ $\mathrm{mm}^{2}$, strain is 0.43 , elastic modulus is $6481.07 \mathrm{~N} / \mathrm{mm}^{2}$, and elongation is $12.5556 \mathrm{~mm}$. And the stress on the second test was $2924.40 \mathrm{~N} / \mathrm{mm}^{2}$, strain of 0.47 , elastic modulus of $6222.12 \mathrm{~N} / \mathrm{mm}^{2}$, and elongation of 12,6108 mm.

Keywords: chain, elastic modulus strain stress, and elongation.

\section{PENDAHULUAN}

Sepeda motor adalah salah satu sarana transportasi darat yang banyak diminati di zaman sekarang. Sepeda motor banyak diminati karena selain harganya terjangkau sepeda motor cocok untuk menempuh daerah - daerah tertentu. Sepeda motor bisa ditunggangi oleh satu orang atau lebih.

Di lingkungan sekitar kita juga dapat dijumpai berbagai macam sepeda motor mulai dari motor sport, motor bebek, dan juga motor matic. Untuk memacu kecepatan motor sport atau motor bebek juga harus di dukung oleh kekuatan rantai. Kekuatan rantai merupakan hal yang harus kita perhatikan karena jika pemasangan rantai tidak sesuai maka performa sepeda motor juga tidak akan bisa melaju dengan kecepatan maksimal.

Masalah yang sering terjadi di lingkungan sekitar kita pada rantai motor yaitu terjadinya kemuluran pada rantai sepeda motor. Kemuluran terjadi Karena sering terjadinya respon dari hentakan yang tak di sengaja, atau pun dikarenakan berat beban pada kendaraan tersebut. Sehingga pada saat kita menempuh perjalanan yang cukup menanjak akan memberikan beban yang besar kepada rantai.

Untuk mengatasi kemuluran tersebut biasanya sering dilakukan perawatan, perawatan sendiri bisa dengan menggunakan pelumas pada rantai tersebut. Pelumas sendiri berfungsi agar rantai tidak aus pada saat digunakan.

\section{KAJIAN PUSTAKA}

\subsection{Tramsmisi}

Transmisi adalah komponen yang ada di mesin dengan fungsi untuk merubah kecepatan dan tenaga dari mesin menuju ke roda yang dapat beregerak. Selain itu, sistem pemindahan tenaga tersebut ada beberapa komponen seperti kopling, deferensial, transmisi, roda dan poros kendaraan. Semua bagian ini saling berhubungan satu sama lain. Mengenai pengertian transmisi manual, posisi serta komponennya ada di ujung depan setelah kopling.

\subsection{Sproket}

Sproket adalah roda bergerigi yang berpasangan dengan rantai, track, atau benda panjang yang bergerigi lainnya. Sproket berbeda dengan roda gigi sproket tidak pernah bersinggungan dengan sproket lainnya dan tidak pernah cocok. Adapun sproket yang digunakan pada sepeda motor Honda CB150R bagian depan menggunakan sproket berukuran $15 \mathrm{~T}$ dan bagian belakang menggunakan sproket berukuran $45 \mathrm{~T}$.
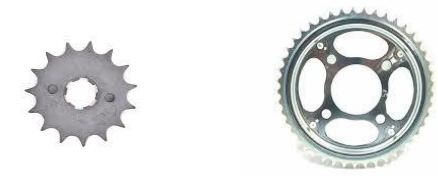

Gambar 2.1 sproket Honda CB150R 


\subsection{Rantai Sepeda Motor}

Rantai adalah salah satu komponen penting dalam sepeda motor, rantai alat yang cukup efisien yang berfungi untuk mentransfer daya antara poros pararel. Rantai juga digunakan untuk menurunkan kecepatan yang relatif sangat besar. Rantai mengait pada gigi sproket dan meneruskan daya tanpa slip sehingga menjamin perbandingan putaran yang tetap. Tanpa adanya rantai dan gigi sprocket maka roda belakang tidak akan dapat berfungsi sebagai penggerak kendaraan.

Bagian - bagian rantai sepeda motor :

1. Plat luar (outer sideplat), yang berfungsi sebagai penyambung antara pin, posisi nya ada di paling luar.

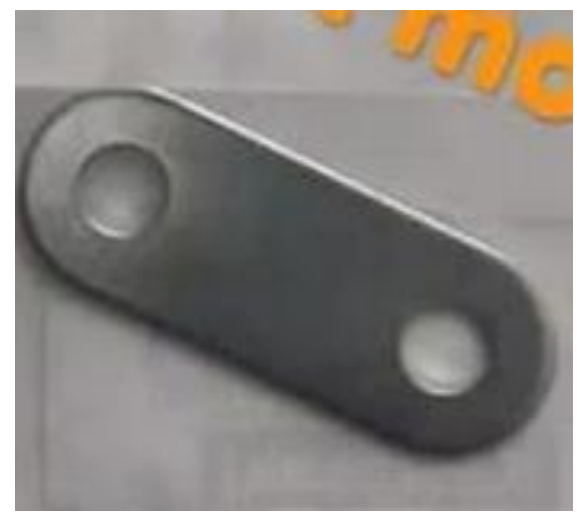

Gambar 2.2 plat luar (outer sideplat)

2. Plat dalam (inner sideplat), yang berfungsi juga sebagai penyambug antara pin.

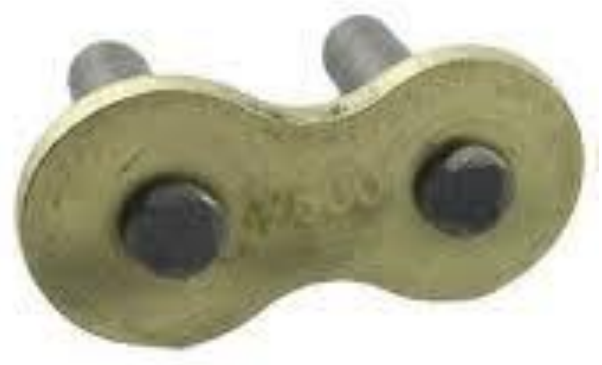

Gambar 2.3 Plat dalam (inner sideplat)

3. Roller chain, fungsi dari roller chain bagian yang berhubungan langsung dengan gigi sproket.

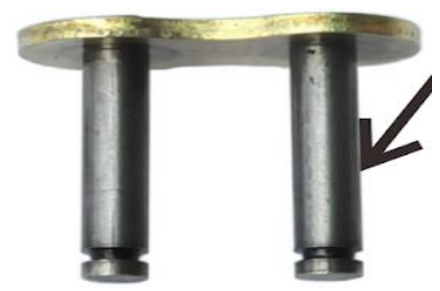

Gambar 2.4 Pin
4. Bus (bushing) berfungsi sebagai pelindung antara roller dengan pin, agar pin tidak langsung bergesekan dengan roller.

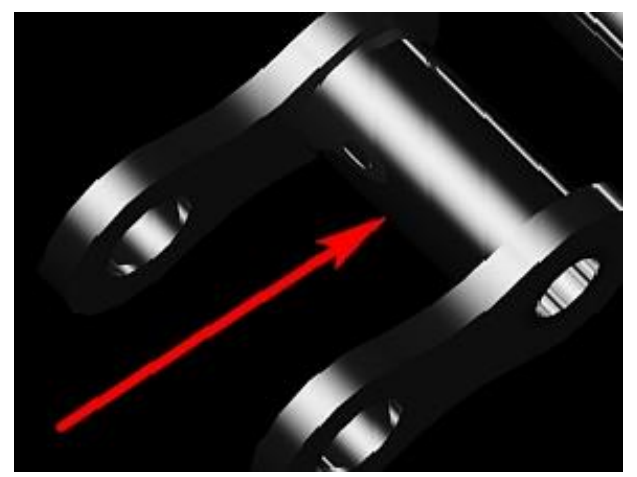

Gambar 2.5 roller chain

\subsection{Kemuluran}

Kemuluran (Creep) Adalah sifat yang menyebabkan beberapa bahan pada tegangan konstan mengalami perubahan bentuk dengan perlahan, tetapi makin lama bertambah dalam suatu selang waktu. Kemuluran terjadi akibat dari perubahan waktu. Mampu mesin (Machinability) adalah kesiapan suatu bahan dibentuk tertentu dengan alat-alat pemotong.

\section{A. Kurva Mulur}

Bertambahnya deformasi bahan pada tegangan tetap dinamakan mulur. Untuk menentukan kurva mulur rekayasa suatu logam, maka pada benda tarik dikenakan beban tetap sedang suhu pada benda ujidijaga tetap, regangan (perpanjangan) yang terjadi ditentukan sebagai fungsi waktu. Walaupun prinsip pengukuran ketahanan mulur sangat sederhana, tetapi pada kenyataannya pengukuran tersebut memerlukan peralatan laboratorium yang cukup banyak. Waktu yang diperlukan dapat berbulan - bulan, bahkan beberapa pengujian memerlukan waktu lebih dari 10 tahun. Prosedur umum mengenai uji mulur terdapat dalam spesifikasi ASTM E139-70 dan JIS (Japanese Industri Standars).

Pada tahap akhir, laju mulur bertambah besar secara cepat hingga terjadi patah. Oleh karena itu, merupakan hal yang wajar bahwa pembahasan kurva mulur ditinjau berdasarkan ketiga tahapan tersebut, sangat tergantung pada suhu dan tegangan yang dikenakan. Dalam melakukan uji mulur rekayasa, biasanya beban beban uji dipertahankan konstan. Jadi sejalan dengan memanjangnya benda uji serta mengecilnya luas penampang lintang, maka tegangan sesumbu (uniaxial) bertambah besar. 


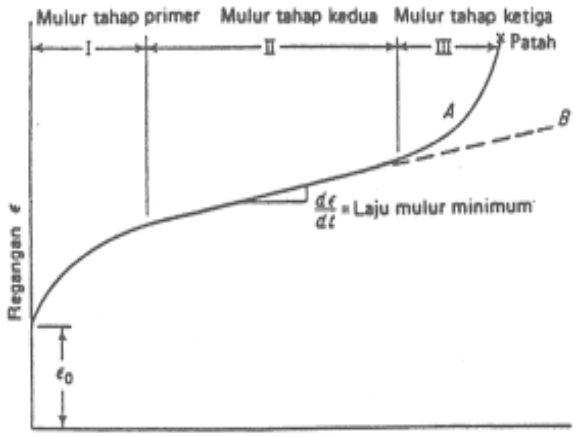

Gambar 2.6 Kurva mulur tipikal yang menggambarkan 3 (tiga) tahapan mulur. Kurva A, uji beban tetap, kurva $B$ uji tegangan tetap

(Metalurgi teknik edisi ketiga jilid)

\section{B. Uji Tegangan Putus}

Uji tegangan putus pada dasarnya serupa dengan uji mulur, dengan catatan bahwa uji tegangan ini selalu dilakukan hingga terjadi kegagalan bahan. Beban yang dih gunakan pada uji tegangan lebih besar disbanding uji mulur, oleh karena itu lajunmulurnya lebih besar. Pada umumnya uji mulur dilakukan pada tegangan tegangan yang relative rendah untuk menghindarkan terjadinya mulur tersier.

Tekanan utama pada uji mulur adalah pada penentuan besarnya regangan secara teliti, khususnya untuk menentukan besarnya laju mulur minimum. Uji mulur seringkali dilakukan untuk waktu yang cukup lama yaitu antara 2.000 jam, bahkan 10.000 jam. Pada uji mulur, regangan totalnya dapat mencapai 50 persen. Jadi, dapat digunakan peralatan pengukur tegangan yang lebih sederhana, seperti pengukur berskala (dial gauge). Peralatan untu uji tegangan putus lebih mudahuntuk disusun, baik perawatannya maupun penggunaannya lebih mudah dibandingkan dengan peralatan uji tegangan putus lebih mudah diubah menjadi unit -unit uji serbaguna. Tegangan dan laju mulur yang lebih tinggi pada uji teganagan putus dapat mengakibatkan terjadinya perubahan struktur logam lebih cepat dibandingkan dengan yang terjadi pada uji mulur biasa.

Informasi dasar yang diperoleh dari uji tegangan putus adalah waktu hingga terjadi kegagalan pada tegangan nominal tertentu untuk suhu tetap tertentu pula. Juga dapat diketahui besar perpanjangan dan pengurangan luas pada saat terjadi kegagalan. Jika uji dilakukan untuk selang waktu yang tepat, mak dapat dilakukan pengukuran perpanjangan sebagai fungsi waktu dan dari pengukuran ini dapat ditentukan besar laju mulur minimum.

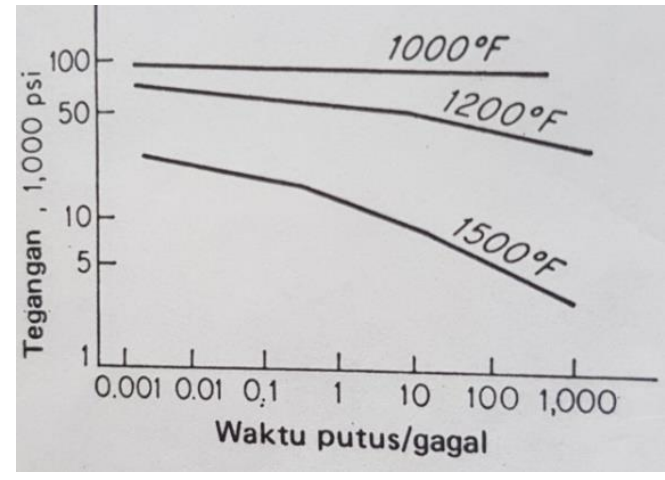

Gambar 2.7 metode pemetaan data tegangan putus / gagal (skematik ) (Metalurgi teknik edisi ketiga jiid 1)

\section{Perubahan Struktur Selama Mulur}

Proses deformasi utama pada suhu tinggi adalah pergelinciran, pembentukan sub butir (subgrain), dan pergelinciran batas butir. Deformasi suhu tinggi ditandai oleh ketidak homogenan yang ekstrim. Pengukuran perpanjangan mulur lokal mengalamai perubahan periodik. Perubahan ini tidak terekam pada perubahan - perubahan regangan dari panjang ukur total benda uji yang bersangkutan. Pada benda uji dengan butir kasar, daerah tertentu dapat mengalami perputaran kisi yang menghasilkan daerah dengan arah menyimpang, (misorientation).

Logam - logam yang berada pada suhu tinggi megalami sejumlah proses deformasi sekunder. Proses ini terdiri atas pergelinciran ganda, pembentukan pita gelincir yang sangat kasar, pita pita tertekuk, pembentukan lipatan pada batas batas butir, dan migrasi batas butir. Banyak kajian mengenai deformasi pada suhu tinggi yang dilakukan dengan benda uji lembaran alumunium yang berbutir kasar.

(Alumunium) merupakan benda uji yang banyak digunakan karena oksida tipis pada permukaan mencegah timbulnya permasalahan oksidasi). Kajian sejenis juga dilakukan pada besi, magnesium dan timah hitam. Merupakan hal yang sangat penting untuk disadari bahwa kajian mengenai deformasi suhu tinggi dilakukan, dalam keadaan dimana laju mulur mencapai nilai berapa persen dalam waktu 100 atau 1.000 jam. Sementara untuk penerapan keteknikan lazimnya, diperlukan laju mulur kurang dari $1 \%$ dalam 100.000 jam. Karena proses deformasi yang terjadi pada suhu tinggi juga tergantung pada laju regangan suhu, mak tidak selalu mungkin untuk mengekstrapulasi hasil - hasil yang diperoleh dari kondisi laju regangan tinggi ke laju regangan yang sering dipergunakan. Banyak uraian mengenai proses deformasi pada saat mulur dikemukakan oleh sully dan grant serta chaudhuri dan lain lainnya. 


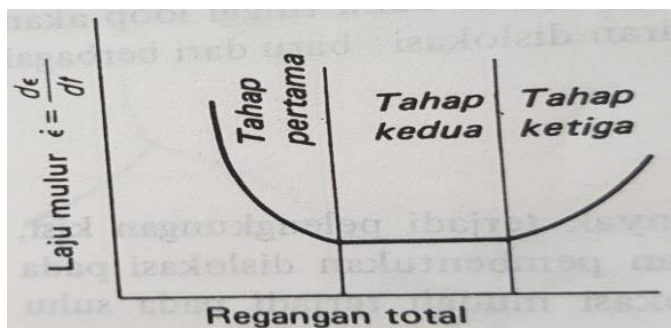

Gambar 2.8 Laju regangan pada uji mulur sebagai fungsi regangan total (Metalurgi teknik edisi ketiga jilid 1)

\subsection{Tegangan}

Tegangan (stress) didefinisikan sebagai perbandingan antara gaya yang bekerja pada benda dengan luas penampang benda.

\subsection{Regangan}

Regangan merupakan ukuran mengenai seberapa jauh batang tersebut berubah bentuk. Tegangan diberikan pada materi dari arah luar, sedangkan regangan adalah tanggapan materi terhadap tegangan.

Dibawah ini merupakan grafik tegangan regangan

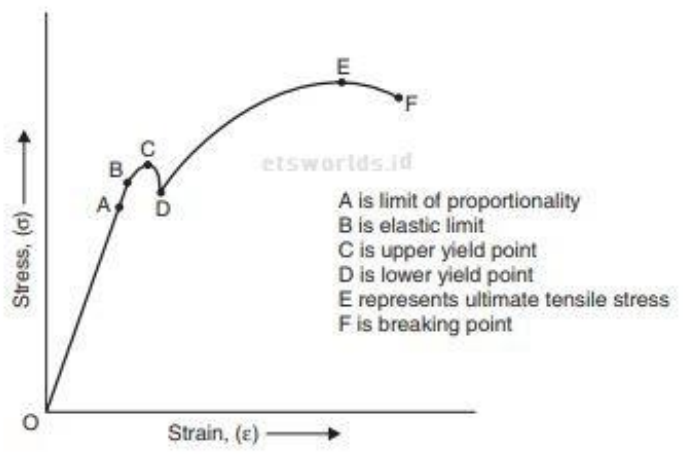

Gambar 2.9 grafik tegangan regangan

\subsection{Modulus Elastis}

Modulus elastisitas adalah angka yang digunakan untuk mengukur objek atau ketahanan bahan untuk mengalami deformasi elastis ketika gaya diterapkan pada benda itu. Modulus elastisitas suatu benda didefinisikan sebagai kemiringan dari kurva tegangan-regangan di wilayah deformasi elastis. Bahan kaku akan memiliki modulus elastisitas yang lebih tinggi.

\section{METODE PENELITIAN}

Metode penelitian yang digunakan yaitu pengujian tarik (Tensile test). Tensile test adalah pengujian kekuatan suatu material dengan menarik suatu bahan sampai putus. Pada tensile test suatu material akan mengalami kerusakan, karena tensile test adalah pengujian kekuatan material dengan menarik suatu material sampai putus. Jadi material yang dites kekuatannya akan rusak. Dengan tujuan untuk menilai batas kemuluran yang terjadi pada sebuah material. Dalam penelitian ini dimulai dari beberapa tahapan-tahapan diantaranya sebagai berikut:

1. Mulai, yaitu mengawali penelitian dengan sebuah perencanaan-perencanaan dimulai dari merencanakan jadwal penelitian.

2. Persiapan alat dan bahan, yaitu mengumpulkan alat dan bahan yang diperlukan untuk berlangsungnya sebuah pengujian.

3. Mempersiapkan mesin uji tarik agar pada saat melakukan pengujian dapat berfungsi dengan normal.

4. Mempersiapkan rantai dan memotongnya sebagai spesimen material untuk dilakukan pengujian.

5. Setelah dilakukannya pemotongan dengan panjang spesimen masing -masing $300 \mathrm{~mm}$.

6. Pengolahan data, yaitu megolah data yang telah dikumpulkan dari hasil pengujian dinamometer.

7. Selesai, yaitu merupakan tahapan akhir dari pengujian dan pengumpulan data-data serta menyusun laporan.

Pengujian dilakukan sebanyak dua kali pengujian diantranya :

1. Pengujian pertama dilakukan dengan rantai sepanjang $50 \mathrm{~mm}$

2. Pengujian dilakukan sampai rantai putus

3. Pengujian kedua dilakukan dengan rantai sepanjang $50 \mathrm{~mm}$

4. Pengujian dilakukan sampai rantai putus

\section{BAHASAN DAN HASIL}

\subsection{Persiapan}

Adapun tahapan yang di lakukan untuk persiapan pengujian tarik (tensile test)sebagai berikut:

1. Persiapan alat atau mesin uji tarik

2. Proses pemotongan rantai

3. Spesimen yang akan diuji

4. Proses pengujian uji tarik

\subsection{Pengujian}

Adapun variasi yang di lakukan dalam pengujian tarik (Tensile test) sebagai berikut:

1. Proses pengujian uji tarik dilakukan sebanyak 2 (dua) kali dan waktu yang diperlukan selama pengujian kurang lebih 5 (lima) menit dengan beban maksimum saat pengujian pertama sebesar $24565 \mathrm{~N}$ dan pengujian kedua sebesar $24345 \mathrm{~N}$ dengan tujuan untuk memperoleh hasil perpanjangan akhir. 


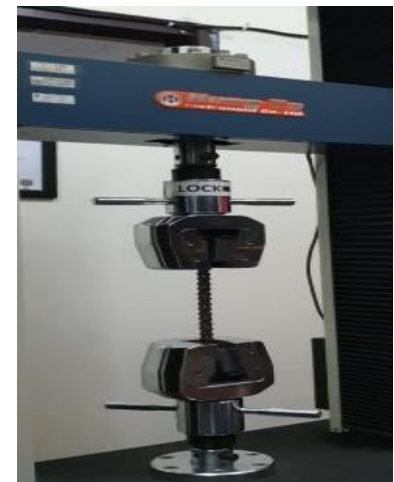

Gambar 4.1 proses pengujia uji tarik

2. Pada saat data yang diperoleh berupa grafik, grafik tersebut yang muncul pada display komputer menunjukkan hasil grafik uji tarik.

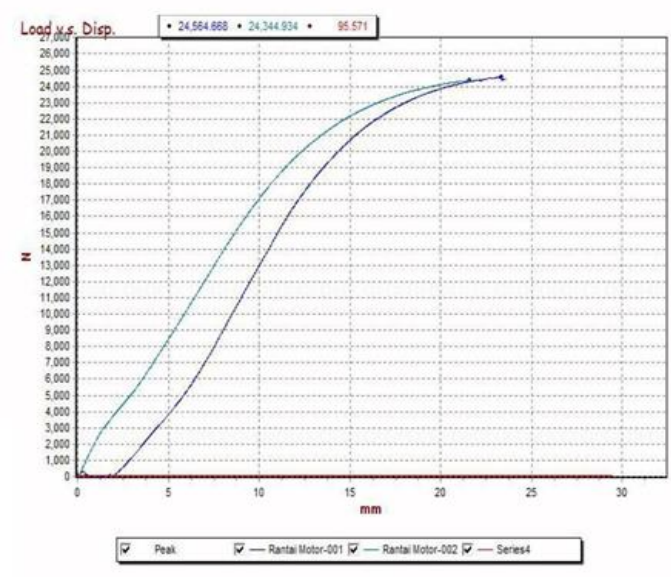

Gambar 4.2 grafik hasil uji tarik

\subsection{Hasil Pengujian}

Hasil pengujian uji tarik pada rantai hasil pengujian uji tarik pada rantai dapat dilihat dalam table 4.1 seperti terlihat pada halaman selanjutnya :

Table 4.1 hasil pengujian

\begin{tabular}{|c|c|c|}
\hline No. Sample Uji & 1 & 2 \\
\hline $\begin{array}{c}\text { Panjang awal, } \\
\mathrm{L}_{\mathrm{o}}(\mathrm{mm})\end{array}$ & 50 & 50 \\
\hline $\begin{array}{c}\text { Beban Maksimum, } \\
\text { F }^{\text {maks }}(\mathrm{N})\end{array}$ & 14335 & 14565 \\
\hline $\begin{array}{c}\text { Beban Luluh, } \\
\mathrm{f}_{\mathrm{y}}(\mathrm{N})\end{array}$ & 18816.35 & 19856.20 \\
\hline $\begin{array}{l}\text { Panjang Akhir, } \\
l_{f}(\mathrm{~mm})\end{array}$ & 71.63 & 73.61 \\
\hline $\begin{array}{l}\text { Kekuatan Tarik, } \\
\text { S }_{\text {UTS }}\left(\mathrm{N} / \mathrm{mm}^{2}\right)\end{array}$ & 241.25 & 243.70 \\
\hline $\begin{array}{c}\text { Kekuatan Luluh, } \\
\mathrm{S}_{\mathrm{y}}\left(\mathrm{N} / \mathrm{mm}^{2}\right)\end{array}$ & 186.67 & 186.67 \\
\hline $\begin{array}{c}\text { Perpanjangan, } \\
\mathrm{e}(\%)\end{array}$ & 43.26 & 47.23 \\
\hline
\end{tabular}

\subsection{Perhitungan Mulur Rantai}

Perhitungan ini bertujuan untuk mengetahui diantaranya besarnya tegangan, regangan, dan modulus young pada sebuah rantai. Standar dari JCAS ( Japan Chain Assosiation Standart). Untuk rantai tipe $428 \mathrm{H}$ (rantai yang digunakan pada sepeda motor) adalah 2,1 ton. Tes ketiga, yaitu uji kemuluran (elongation test). Rantai diputar dynamo dengan beban $70 \mathrm{~kg}$ dan $2000 \mathrm{rpm}$. Tes ini dilakukan selama 2 x 25 jam atau setara $10.000 \mathrm{~km}$. agar lolos standar JCAS, rantai maksimal bertambah mulur sebesar $0,7 \%$.

Table 4.2 hasil tegangan dan regangan

\begin{tabular}{|c|c|c|}
\hline No Pengujian & Tegangan & Regangan \\
\hline 1 & $2898.21 \mathrm{~N} / \mathrm{mm}^{2}$ & 0.43 \\
\hline 2 & $2924.40 \mathrm{~N} / \mathrm{mm}^{2}$ & 0.47 \\
\hline
\end{tabular}

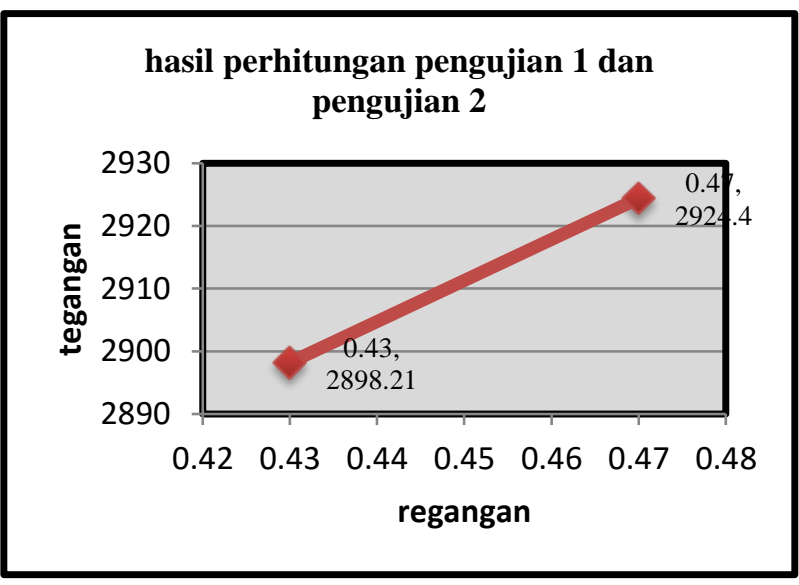

Gambar 4.3 grafik hasil perhitungan

Tegangan regangan 1 dan 2

Tabel 4.3 hasil kemuluran

\begin{tabular}{|c|c|}
\hline No pengujian & Kemuluran \\
\hline 1 & $12.5556 \mathrm{~mm}$ \\
\hline 2 & $12.6108 \mathrm{~mm}$ \\
\hline
\end{tabular}

\section{kemuluran}

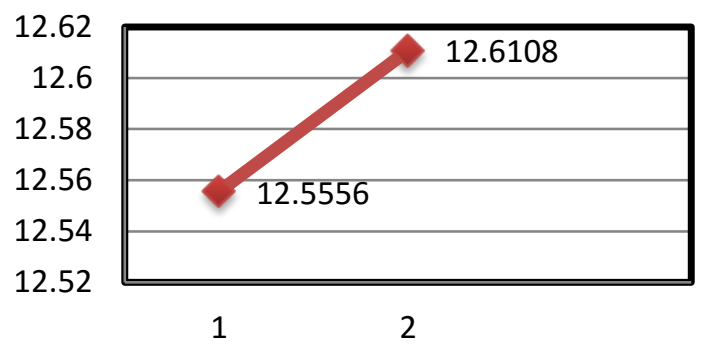

Gambar 4.4 grafik total kemuluran 


\section{Kesimpulan Dan Saran}

\subsection{Kesimpulan}

Dari hasil penelitian yang dimana dengan melakukan analisis kemuluran rantai pada sepeda motor Honda CB150R dengan model rantai $428 \mathrm{H}$ dari hasil dua kali pengujian dengan satu spesimen dapat disimpulkan bahwa :

1. Dalam pengujian yang kedua tegangan $\sigma$ yang terjadi sebesar $2898,21 \mathrm{~N} / \mathrm{mm}^{2}$, regangan $\varepsilon$ yang terjadi sebesar 0,43 , dan modulus elastis $E$ yang terjadi sebesar $6481,07 \mathrm{~N} / \mathrm{mm}^{2}$, serta kemuluran yang terjadi sebesar $12.5556 \mathrm{~mm}$.

2. Dalam pengujian pertama tegangan $\sigma$ yang terjadi sebesar $2924,40 \mathrm{~N} / \mathrm{mm}^{2}$, regangan $\varepsilon$ yang terjadi sebesar 0,47 , dan modulus elastis $E$ yang terjadi sebesar $6222,12 \mathrm{~N} / \mathrm{mm}^{2}$ serta kemuluran yang terjadi sebesar $12.6108 \mathrm{~mm}$.

Jadi setelah menganalisis kemuluran rantai pada sepeda motor Honda CB150R maka kemuluran rata - rata yang di dapat sebesar 12,5832 $\mathrm{mm}$. Sedangkan hasil yang di dapat dari standar yang dikeluarkan JCAS (Japan Chain Aassosiation Standart) adalah sebesar $0,7 \%$ atau sebesar $11,06 \mathrm{~mm}$. Dapat disimpulkan bahwa hasil pengujian dan hasil yang di keluarkan JCAS ada selisih perbedaan sebesar $1,5232 \mathrm{~mm}$.

\subsection{Saran}

Kemuluran yang terjadi pada rantai model $428 \mathrm{H}$ sebesar $12,5832 \mathrm{~mm}$ maka perlu diadakan penelitian selanjutnya dengan model rantai lain untuk mengetahui pembanding manakah jenis rantai yang lebih tahan terhadap kemuluran.

\section{DAFTAR PUSTAKA}

1. Adnan Kemal Pasha, Riki Andra Putra, 2018, Analisis kemuluran rantai sepeda motor terhadap usia pemakaian rantai, Tangerang : Lembaga penelitian Universitas Muhammadiyah Tangerang

2. George E. Dieter, Ir. Ny. Sriati Djaprie M.E, M.Met, 1998, Metalurgi teknik edisi ketiga jiid 1 (satu), University of Maryland, Universitas Indonesia, Erlangga, Jakarta.

3. George E. Dieter, Ir. Ny. Sriati Djaprie M.E, M.Met, 1996, Metalurgi teknik edisi ketiga jiid 2 (dua), University of Maryland, Universitas Indonesia, Erlangga, Jakarta.

4. E . P. Popov, Zainul Astamar, 1986, Mekanika teknik (Mechanics of materials) edisi kedua (versi si), University of California, Berkeley, Universitas Krisnadwipayana, Erlangga, Jakarta. 